\title{
La rapidez y eficacia en la Administración
}

\author{
por \\ JOSE M.` CIURANA FERNANDEZ \\ Doctor en Derecho \\ Secretario del Ayuntamiento de San Baudilio de Llobregat
}

La RaPidez y eficacia en la Administración

Es realmente esperanzador el movimiento que actualmente se está promoviendo en favor de la racionalización de la Administración del Estado, aplicando en ella muchos de los principios y postulados que utilizan las empresas de tipo mercantil. Como es lógico, esta corriente renovadora se nota también en España, en donde prescindiendo de algunos estudios de carácter teórico (1), poco se había hecho hasta que, desde la Subsecretaría de la Presidencia y por medio de la revista "Documentación Administrativa", se está efectuando una verdadera transformación teórica y práctica, que va desde la difusión de los grandes principios de organización administrativa, hasta el estudio de los tiempos y los movimientos en la realización de las

(1) Como el que publicó el firmante en la Revista Moderna de Administración Localı, de Barcelona, números de septiembre de 1940 a junio de 1941, bajo el título La racionalización de la Administración del Estado y del Municipio, en donde se explicaban los p:incipios de organización científica expuestos por Federic W. TAYLOR y Henty Fayol, así como se trataba de su posible apiicación tanto al Estado como al Municipio. 
diversas tareas burocráticas, o en la normalización de documentos:

Esto, con el tiempo, dará lugar a que los funcionarios dirigentes de la Administración, en su trabajo, apliquen la duda metódica preconizada por Descartes en filosofía y ante la tarea cotidiana se pregunten, como los técnicos de las empresas: "¿Por qué se hace esto de esta forma? ¿No podría realizarse de otro modo de manera que se ahorrase tiempo y esfuerzo y con ello se aumente el rendimiento del trabajo administrativo?

Claro que el funcionario se encuentra en una posición algo diferente si se le compara con su homónimo en la empresa. $\mathrm{Ha}$ de tener muy en cuenta el aspecto jurídico de los asuntos, a fin de respetar los derechos de los administrados, pero aún así, el campo de actuación en que predomina puramente lo técnico es en realidad muy extenso y los resultados que puedan llegar a conseguirse son también dignos de consideración. El mismo Henry Fayol decía a este particular que no existe una doctrina administrativa para la industria y una doctrina administrativa para el Estado; no hay más que unos principios de organización administrativa que son aplicables tanto a unos como a otros (2).

\section{LENTITUD EN EL TRÁMITE ADMINISTRATIVO}

Ante todo, hay que reconocer que tanto la Administración del Estado como la de las grandes Corporaciones locales pecan por ser demasiado lentas y engorrosas. El peso de siglos de burocracia ha actuado y sigue actuando como un verdadero freno en el desenvolvimiento de la labor administrativa, siempre influenciada por la práctica y la rutina.

$Y$ como no es nuestro propósito realizar un estudio de carácter teórico ni tampoco criticar sin objetivo alguno, vamos a

(2) Prólogo de H. Fayol en su libro L'éveil de l'esprit public, París, 1927, página 0 . Con referencia a la analogía entre la admin stración del Municipio I la de as empresas industriales, véase Municipio y empresa mercantil, articuJo publicado en esta misma Revista de Estudios de la Vida Local, en el número 2 de 1942. 
ilustrar todas estas consideraciones con un caso práctico, dentro del campo de la Administración municipal, por ser éste el lugar en donde desarrollamos nuestra actividad profesional.

Decimos que la Administración es lenta y engorrosa. Supongamos el caso de un Municipio comprendido entre los $10.000 \mathrm{~g}$ 20.000 habitantes y que se trata de la construcción de unas aceras, cuyo presupuesto total llega, por ejemplo, a las 17.000 pesetas. En tal caso, por exceder de las $\mathbf{1 5 . 0 0 0}$ pesetas, es obligatorio el trámite de la subasta, como norma general. Esto supone que han de cumplirse los siguientes trámites y plazos desde que el Alcalde, por oficio, o la Comisión Municipal Permanente, mediante acuerdo, encargan al técnico municipal correspondiente (Arquitecto o Ingeniero), la confección del oporturio proyecto:

1. Formación del proyecto técnico (un mes);

2. Aprobación de éste por la Comisión Municipal Permanente, previo informe de la Comisión de Fomento u Obras, y posterior exposición al público, en el Bolctín Oficial de la Provincia, por el plazo de quince días al efecto de reclamaciones (dos meses);

3. Remisión de dicho proyecto a la Comisión Provincial de Servicios Técnicos de la Excma. Diputación Provincial, para su superior aprobación, trámite en el que se tarda unos tres meses ;

4. Nuevo acuerdo del Ayuntamiento diciendo que se proceda a la subasta. Exposición al público en el Boletin Oficial de la Provincia por ocho días hábiles de los pliegos de condiciones, y a continuación anuncio de la subasta, también en el Boletín Oficial de la Provincia, por veinte dias hábiles (otros dos meses). Hay que recordar que la remisión de anuncios al Boletin Oficial de la Provincia se hace por conducto de los respectivos Gobiernos ciles, lo cual, naturalmente, alarga un poco más la tramitación;

5. Celebración de la sul)asta, con su adjudicación provisional y luego, transcurridos tos dias reglamentarios por si hubiese reclamaciones, se efectúa, mediante acuerdo, la adjudicación 
definitiva con prestación de la fianza, después de lo cual pueden empezarse las obras (otro mes).

O sea, en definitiva, que desde que se decide la realización de una obra hasta que ésta pueda empezar a construirse pasan como mínimo unos nueve meses, suponiendo siempre que exista la debida consignación en el presupuesto ordinario, que no se tropiece con las vacaciones estivales, en cuyo caso los plazos se alargarian más, y que la Comisión Provincial de Servicios Técnicos no ponga reparo alguno al proyecto. Esto, tratándose de obras sencillas, como el terraplenado de una calle, colocación de bordillos, construcción de un trozo de alcantarilla, aceras, etc., en las cuales no existe complicación alguna y son de poco coste, es trancamente ridículo. Si la empresa mercantil para realizar algo semejante tuviese que esperar tanto tiempo y efectuar tantos trabajos previos, los negocios y toda la vida económica andarían a paso de tortuga.

Cuando a veces acuden a nuestra Secretaría para consultar los vecinos sobre si se tardaría mucho para colocar unos bordillos en una nueva calle y hemos de informarles de una tramitación tan laboriosa, no sabemos qué razones darles para justificarlo. Podríamos limitarnos a decir que lo exige así la Ley y basta; pero no encontramos correcto desacreditar de esta forma a las leyes y estimamos preferible seguir por otro camino distinto y ver si es posible evitar tanta tramitación y abreviar un poco más los plazos.

Alguien podria objetar que, por el hecho de la subasta, económicamente se sale siempre ganando, ya que ésta se concede al mejor postor, pero esto no es más que un espejismo, ya que la subasta implica: tener que pagar los anuncios en el Bolctín. Oficial de la Provincia y además, liqu:dar el impuesto de derechos reales y timbre. Como los postores ya saben que esto supone un recargo del 10 o el 15 por 100 , todos estos gastos los incluyen en la oferta que presentan, la cual resulta asi aumentada en consecuencia. 


\section{UN REMEDIO: LAS ASOCIACIONES DE VECINOS}

Dentro de las posibles soluciones, hemos utilizado, como más rápido y económico, el de asociar a los propios vecinos, que, sin formulismos en cuanto a su constitución, se reúnen y con un contratista amigo se enteran del coste de la obra, y si ven que pueden pagarla se dirigen al Ayuntamiento solicitando permiso para ello. Les contesta éste diciendo que para esto deben observarse las condiciones técnicas ya establecidas en casos semejantes (ejemplo: que los bordillos han de ser de piedra arenisca, las aceras han de construirse con panots hidráulicos, etcétera) y entonces la obra es efectuada directamente por dicho contratista, siempre bajo la vigilancia de los técn:cos municipales $\mathrm{y}$ de los mismos vecinos interesados. Al objeto de colaborar con éstos, el Ayuntamiento luego se cuida de efectuar el reparto, cobrando las cuotas respectivas por medio de recibos firmados por los representantes de los expresados vecinos, quedando las cuotas depositadas en la Casa Consistorial para mayor seguridad de todos ; después, se paga al contratista, en nombre de los vecinos, y el asunto queda concluido.

Este procedimiento tiene varias ventajas, tanto por lo que se refiere al Ayuntamiento, como a los vecinos en general. Para el Ayuntamiento, porque no consume crédito del Presupuesto, evita papeleo y se facilita el que las obras sencillas, de poca envergadura, puedan realizarse con toda rapidez. Para los vecinos las ventajas son también iguales o mayores: máxima economía, ya que sólo tienen que pagar el coste neto de la obra, evitándose los gastos del proyecto técnico, anuncios ofic:ales, derechos reales y timbre; gran rapidez en la ejecución de la obra; el contratista es escogido por los propios interesados, por lo que goza de la confianza de todos, siendo imposibles las confabulaciones y abusos, por cuanto los precios de los materiales y jornales son generalmente conocidos y muy especialmente por los contratistas rivales del que hace la obra, que en segui- 
da lo pregonarian a los cuatro vientos en caso de que se pretendiese hacer pagar más de lo debido.

En este caso de asociaciones de vecinos no hay contratación administrativa ni, por tanto, puede exigir el Ayuntamiento "obligatoriamente" el pago de las cuotas, pues no se trata de contribuciones especiales de inejora, sino de aportaciones voluntarias efetuadas por los vecinos para una obra determinada.

\section{Naturaleza Jurídica dE ESTa FORMa dE EJECUCión DE OBRAS}

Dentro de las disposiciones legales vigentes esta realización voluntaria de obras, mediante la colaboración de los propios beneficiados, ¿qué figura jurídica será la que mejor le cuadre? Este problema es interesante, porque, resolviendo una consulta acerca de esta materia, el Servicio de Inspección y Asesoramiento de las Corporaciones Locales opina que no es posible eludir las normas dictadas para la contratación administrativa, debiendo, por lo tanto, atenerse a los preceptos que regulan esta materia y que se refieren a la obligatoriedad del concurso o subasta, salvo raras excepciones.

Esta contestación es correcta y legal, pero en ella no se tiene en cuenta el caso de la donación. No diremos que sea corriente, pero sí se da con alguna frecuencia, en poblaciones en donde existe una empresa importante o una colonia veraniega, el que se realicen obras en la vía pública por cuenta y riesgo de la citada empresa o de dichos veraneantes. Conocemos casos concretos en poblaciones de la Provincia de Barcelona, en las cua'es una gran empresa ha costeado íntegramente el pavimento de la calle en que está emplazada la fábrica de la misma, hasta enlazarla con otra vía ya urbanizada. En otra población, los veraneantes pagaron en su totalidad el coste de la urbanización de una plaza pública. Finalmente, el mismo Ayuntamiento de Barcelona, por medio de asociaciones de vecinos (denominadas, textualmente, "Comisión de vecinos para promover el nuevo alumbrado de la calle», según reza un oficio 
que tenemos a la vista), impulsa el cambio y mejora del sistema de alumbrado público en diversas calles de la Ciudad condal.

En todos estos casos no hay proyecto oficial, ni concurso, ni subasta, ni cualquiera otra formalidad administrativa. Se efectúa la obra por cuenta y riesgo de los interesados y luego se entrega al Ayuntamiento. $\mathrm{Ha}$ de entenderse, pues, que se trata de una donación que hacen los particulares y para lo cual los Municipios tienen plena capacidad para aceptar o rechazar.

Pues bien, esta es la figura jurídica más apropiada a nuestro caso: el de la donación. Si una empresa mercantil coloca bordillos y pavimenta una calle, a la que dan otros vecinos, también pueden hacer lo mismo, con carácter general, los propietarios de terrenos lindantes con una calle cualquiera, con la ventaja, además de que en nuestro supuesto siempre hemos contado con la vigilancia técnica de los funcionarios municipales. El hecho de que el reparto se haga desde el Ayuntamiento y que las cuotas se depositen en el mismo, no quiere decir nada, ya que todo se hace para colaborar y no implica reconocimiento especial de derechos y deberes por parte alguna. Si un vecino no quiere pagar, no se le puede obligar. Todos han de estar conformes, voluntariamente, en efectuar una determinada obra.

Este procedimiento es práctico y sencillo, especialmente para los Municipios de poca importancia, que de esta manera podrän realizar muchas obras a precio de coste, sin gravar a sus presupuestos, con toda rapidez y con el agrado del vecindario.

\section{¿Funcionario robot o funcionario con iniciativa?}

Para el funcionario lo más cómodo sería indudablemente limitarse al texto de la Ley, interpretada según constumbre establecida y seguir con las prácticas tradicionales para evitarse toda clase de complicaciones y responsabilidades. Mas con esto se convertiria en una especie de máquina, al limitarse a la monótona repetición de una serie de trámites, siempre los mismos, sin que nunca se le ocurra pensar el porqué las cosas se hacen de una determinada forma y no de otra. 
Frente a este tipo de funcionaro-robot hay que oponer el concepto de funcionario moderno, siempre dispuesto, dentro de la más estricta legalidad, a probar nuevas fórmulas y a ensayar otros caminos para lograr que la Administración pueda acomodarse a las exigencias de los tiempos modernos y su rendimiento sea lo suficientemente elevado para que pueda reconocerse que en ella también es posible aplicar aquel principio de organización cientifica del trabajo que tanto predomina en las empresas mercantiles y que se concreta en este slogan: máxima producción con el mínimo esfuerzo (3).

(3) José Gardó : Métodos de trabojo, Barcelona, 1944, pág. 19. 